\title{
Erratum to: Estrous cycle and sex affect cocaine-induced behavioural changes in CD1 mice
}

\author{
Mariangela Martini • Ana Xavier Pinto • Olga Valverde
}

Published online: 3 February 2015

(C) Springer-Verlag Berlin Heidelberg 2015

\section{Erratum to: Psychopharmacology 231:2647-2659 DOI 10.1007/s00213-014-3433-5}

Regarding the article "Estrous cycle and sex affect cocaineinduced behavioural changes in CD1 mice" by M. Martini, A. Xavier Pinto and O. Valverde, published in Psychopharmacology 231: 2647 (2014), the authors regret having used several sentences in the Introduction section from another publication without specific attribution. In particular, the Van Swearingen et al. (2013b) reference, included in the Reference section, should be added to the end of the following sentences: "Women are more sensitive..." and "These observed sex differences ..." in the first paragraph; "Females work harder for psychostimulants..." and "These observations have made the rat..." in the second paragraph; and "Psychostimulants like cocaine..." and "Psychostimulants elicit both enhanced locomotion..." in the third paragraph. Two additional citations were omitted in the third paragraph: Kelly et al., (1975), and
Kuhn et al., (2010). The authors apologize for these errors of omission.

\section{References}

Kelly PH, Seviour PW, Iversen SD (1975) Amphetamine and apomorphine responses in the rat following 6-OHDA lesions of the nucleus accumbens septi and corpus striatum. Brain Res 94:507-22

Kuhn C, Johnson M, Thomae A, Luo B, Simon SA, Zhou G, Walker QD (2010) The emergence of gonadal hormone influences on dopaminergic function during puberty. Horm Behav 58:122-37

Van Swearingen AED, Walker QD, Kuhn CM (2013) Sex differences in novelty- and psychostimulant-induced behavior of C57BL/6 mice. Psychopharmacology 225:707-718

The online version of the original article can be found at http://dx.doi.org/ 10.1007/s00213-014-3433-5.

M. Martini $\cdot$ A. X. Pinto $\cdot$ O. Valverde $(\triangle)$

Neurobiology of Behaviour Research Group (GReNeC), Department of Health and Experimental Sciences, Universitat Pompeu Fabra, Barcelona Biomedical Research Park C/Dr. Aiguader 88, 08003 Barcelona, Spain

e-mail: olga.valverde@upf.edu

Present Address:

M. Martini

Equipe "Neuropsychopharmacologie de l'Addiction", Institut de Neurosciences Cognitives et Intégratives d'Aquitaine, UMR CNRS

5287, 33076 Bordeaux, France 